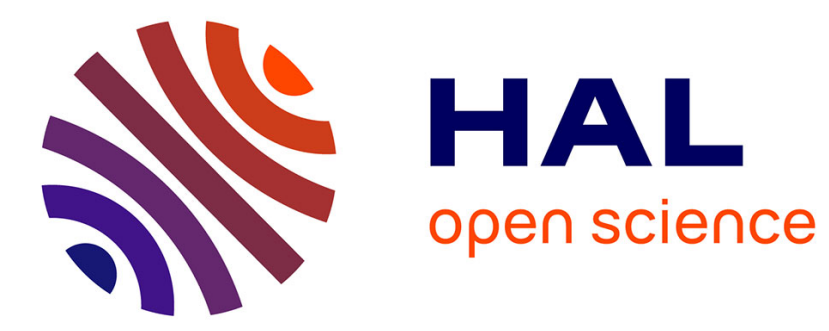

\title{
Stronger impulse capture and impaired inhibition of prepotent action in children with ADHD performing a Simon task: an electromyographic study
}

Aurélie Grandjean, Isabel Suarez, Elisa Diaz, Laure Spieser, Boris Burle, Agnès Blaye, Laurence Casini

\section{To cite this version:}

Aurélie Grandjean, Isabel Suarez, Elisa Diaz, Laure Spieser, Boris Burle, et al.. Stronger impulse capture and impaired inhibition of prepotent action in children with ADHD performing a Simon task: an electromyographic study. Neuropsychology, In press. hal-03175710

\author{
HAL Id: hal-03175710 \\ https://hal.science/hal-03175710
}

Submitted on 20 Mar 2021

HAL is a multi-disciplinary open access archive for the deposit and dissemination of scientific research documents, whether they are published or not. The documents may come from teaching and research institutions in France or abroad, or from public or private research centers.
L'archive ouverte pluridisciplinaire HAL, est destinée au dépôt et à la diffusion de documents scientifiques de niveau recherche, publiés ou non, émanant des établissements d'enseignement et de recherche français ou étrangers, des laboratoires publics ou privés. 


\title{
Stronger impulse capture and impaired inhibition of prepotent action in children with ADHD performing a Simon task: an electromyographic study
}

\author{
Aurélie Grandjean ${ }^{1}$, Isabel Suarez ${ }^{2}$, Elisa Diaz ${ }^{2}$, Laure Spieser ${ }^{1}$, Boris Burle $^{1}$, Agnès Blaye ${ }^{3}$, \\ Laurence Casini ${ }^{1}$ \\ 1. Laboratoire de Neurosciences Cognitives, FR 3C, Aix-Marseille Université, CNRS, \\ Marseille, France \\ 2. Universidad del Norte, Baranquilla, Colombia
}

3. Laboratoire de Psychologie Cognitive, FR 3C, Aix-Marseille Université, CNRS, Marseille, France

\section{e-mail addresses :}

aurelie.grandjean@univ-amu.fr

suarez.isabel1982@gmail.com

laure.spieser@univ-amu.fr

boris.burle@univ-amu.fr

agnes.blaye@univ-amu.fr

laurence.casini@univ-amu.fr

\section{Corresponding author:}

Laurence Casini

Address : LNC, FR 3C, Case C

3 place Victor Hugo

13331 Marseille cedex 3, France

e-mail : laurence.casini@univ-amu.fr

Phone : 33413550941

Fax : 33413550958

\section{Note}

This work was funded by the French Agence Nationale de la Recherche (ANR-15-CE280008, DOPCONTROL). The authors wish to thank Solène Ambrosi for the development of the program and they also warmly thank all the children that accepted to participate in this study as well as the Universidad Del Norte, and the Colegio Sagrado Corazón of Barranquilla for allowing us to conduct this study. The authors also thank Jennifer Coull for her help with English language. 


\section{Abstract (200 words)}

Objective: A deficit in interference control is commonly reported in children with attention deficit hyperactivity disorder (ADHD). This has mainly been interpreted as a difficulty in inhibiting inappropriate responses. However, it could be due to at least two distinct and independent processes, which are often confounded: the activation or suppression of impulsive responses. The aim of the present study was to separate the contribution of these two processes. Method: We compared performance of 26 children with ADHD to that of 26 non-ADHD children using a novel approach based on electromyographic activity (EMG) analysis. EMG allows two distinct indices to be computed: incorrect activation rate, which is an index of the intensity of impulse capture and correction rate, which provides a direct measure of the ability to suppress automatic responses. Results: Children with ADHD were slower, committed more errors, and had a larger interference effect than non-ADHD children. Moreover, we observed a greater incorrect activation rate and a lower correction rate in the ADHD group. Conclusions: Our data suggest that the difficulties in interference control found in children with ADHD are explained by both impaired inhibitory processes and a greater propensity to activate automatic responses.

Keywords: ADHD, cognitive control, inhibition, response impulsivity, EMG 


\section{Key Points:}

- We investigated how ADHD affects impulsivity control.

- Interference control was impaired in children with ADHD

- Impulsivity and hyperactivity could be due to both a greater propensity to activate impulsive responses and a greater difficulty in inhibiting them.

- Future research should investigate the effect of treatments on these two components of impulsivity control. 
Impulse capture and inhibition in ADHD

Imagine that you are approaching a traffic light that just turned amber. You prepare to brake but suddenly, in your mirror, you see a huge truck coming up very quickly behind you. The safest response is actually to accelerate. This situation therefore requires overlearned automatic actions to be overridden by controlled ones. Every day, we are forced to adapt our behavior to unexpected environmental changes. This flexibility requires efficient cognitive control, a term that refers to the set of processes that are engaged when we must stop inappropriate spontaneous actions in favor of goal-directed actions that are better adapted to the context.

Experimentally, cognitive control has commonly been studied in conflict tasks specifically designed to induce a conflict between an automatic tendency to respond to an irrelevant but salient stimulus and a controlled goal-directed response to a relevant stimulus (Eriksen \& Eriksen, 1974; Simon, 1969; Stroop, 1935). The well-documented Simon task is particularly suitable for studying cognitive control (Hommel, 2011). In the standard version of the Simon task, the participants are required to respond as quickly and as accurately as possible by pressing on a left- or a right-hand key in response to a non-spatial attribute (form or color, for example) of a stimulus that is presented either on the left or right side of a central fixation point. Typically, mean reaction times (RT) are longer and errors are more frequent in trials for which the required response is contralateral to stimulus location (incongruent trials, IG) than in trials where the required response is ipsilateral to stimulus location (congruent trials, CG). This behavioral cost is known as the interference effect. The usual interpretation of these findings is that the position of the stimulus activates a fast and automatic response in the effector ipsilateral to the stimulus. Since this response is erroneous in IG trials, it must be suppressed in favor of the response that is correct according to task instructions. The competition between these two responses is thought to be at the origin of the conflict, with the 
Impulse capture and inhibition in ADHD

suppression of the automatic response requiring interference control (De Jong, Liang \& Lauber, 1994; Kornblum, Hasbroucq \& Osman, 1990; Kornblum, 1994; Lu \& Proctor, 1995).

Several studies (for an overview, see Mullane, Corkum, Klein, \& McLaughlin, 2009) but not all (Borella, de Ribaupierre, Cornoldi, \& Chicherio, 2013; Schwartz \& Verhaegen, 2008; Van Mourik et al., 2009) have found that children with ADHD manifest poor performance in conflict tasks. They exhibit longer reaction times, more errors, and larger interference effects than their typically developing peers (Cao et al., 2013; Homack \& Riccio, 2004; Jonkman, et al, 1999; Tsal, Shalev, \& Mevorach, 2005; for a review, see Mullane, Corkum, Klein, \& McLaughlin, 2009). ADHD is among the most prevalent and most extensively studied of the childhood pathologies. Classically, the difficulties that children with ADHD show in this type of task are considered to be due to difficulties in inhibiting inappropriate automatic and prepotent responses (Barkley, 1997; Nigg, 2001), even if some studies more recently suggest that inhibition may also be intact in children with ADHD (Coghill, Seth, \& Matthews, 2014). However, these difficulties could be due to, at least, two distinct and dynamic processes involved in interference control, which are confounded in most studies. According to the "activation-suppression model" (Ridderinkhof, 2002), the first process, which we will call impulse capture, is assumed to reflect the degree to which the response system is susceptible to activating location-driven automatic responses. The second process is assumed to reflect inhibitory control, which builds up to suppress the interference induced by the incorrect action impulse. Therefore, impairments in children with ADHD could be due either to stronger impulse capture, to less efficient inhibitory processes, or both. Obviously, a better understanding of difficulties in interference control would help to better understand ADHD.

The aim of the present study was to disentangle the contribution of these two processes using electromyographic activity (EMG), which allows for the computation of two 
Impulse capture and inhibition in ADHD

distinct indices that provide information on both the intensity of impulse capture and the ability to inhibit automatic response activation.

\section{EMG activity and interference control}

In choice RT tasks, recording EMG activity of the muscles primarily involved in making a response allows response activation and execution to be studied. It reveals that in about $20 \%$ of correct responses, EMG activity associated with the correct response is preceded by an earlier sub-threshold EMG activity recorded from the hand associated with the incorrect response (see Figure 1) (Eriksen et al., 1985; Hasbroucq, Burle, Akamatsu, Vidal \& Possamaï, 2001; Hasbroucq, Possamaï, Bonnet, \& Vidal, 1999). This sub-threshold activity is called a partial error (Burle, Possamaï, Vidal, Bonnet \& Hasbroucq, 2002). Such incorrect response activations are more numerous in incongruent trials (in which the task-irrelevant affordance primes the incorrect response) than in congruent trials (in which there is response capture of the correct response). It has been proposed that partial errors are the direct manifestation of online activation, and subsequent suppression, of an incorrect automatic response (Burle, Possamaï, Vidal, Bonnet \& Hasbroucq, 2002; Van den Wildenberg et al., 2010). In other words, partial errors correspond to incorrect response activations that have been detected, stopped and corrected. Therefore, partial errors, which reveal subliminal activation of the incorrect response effector and its subsequent correction, constitute a key element in investigating interference control and highlight the utility of EMG recording when studying processes involved in interference control.

\section{INSERT FIGURE 1 ABOUT HERE}

Partial errors provide access to information that is invisible in purely behavioral experiments. More precisely, they reveal information that is hidden in correct trials and allows three types of responses to therefore be distinguished : Pure correct responses correspond to 
Impulse capture and inhibition in ADHD

trials in which there is a unique response-related EMG activity in the correct hand, partial errors correspond to trials with sub-threshold muscle activity in the incorrect hand prior to the EMG activity associated with the correct response, and overt errors correspond to trials with a response-related EMG activity in the incorrect hand only. Using these different types of trials, two different indices highlighting the two processes of interest can be computed. First, the incorrect activation rate (IAR), corresponding to the sum of partial errors and overt errors (that is the total number of incorrect activations, corrected or not) divided by the total number of trials, is considered to provide a direct measure of the intensity of impulse capture, independent from potential subsequent suppression, when it is calculated for incongruent trials in which the stimulus position primes the incorrect response. A higher incorrect activation rate in incongruent trials indicates stronger impulse capture, that is an increased tendency to activate automatic responses (Hasbroucq, Burle, Vidal \& Possamaï, 2009; Van den Wildenberg et al., 2010). Second, the correction rate, corresponding to the number of successfully corrected incorrect activations (that is, partial errors) divided by the overall number of incorrect activations (corrected or not), is considered to provide a direct measure of the ability to suppress automatic responses in order to prevent response errors (Burle, Possamaï, Vidal, Bonnet \& Hasbroucq, 2002; Van den Wildenberg et al., 2010). A lower correction rate indicates less efficient suppression of erroneous automatic responses.

We compared performance of children with ADHD to that of children without ADHD matched in age and education level, and we used classic behavioral measures as well as the two indices derived from EMG activity to investigate the effect of ADHD on two components of interference control: activation and suppression of impulsive responses. In addition, since EMG activity also allows RT to be decomposed into distinct premotor and motor components (Figure 1), we used it to investigate the effect of ADHD separately on motor and decisional processes. 


\section{Material and methods}

\subsection{Participants}

We tested two groups of participants: 26 participants with ADHD (mean age $=11.5 ; 20$ males) and 26 children without ADHD (non-ADHD group) (mean age $=11.4 ; 20$ males) matched in age, school level and socioeconomic status ${ }^{1}$ to children with ADHD. The primary language of all participants was Spanish. All participants and their parents gave informed consent prior to the experiment. The study was approved by the Ethical Committee of the Universidad del Norte (Barranquilla, Colombia) and was carried out in accordance with the provisions of the Declaration of Helsinki.

\subsubsection{Selection procedure for the ADHD group}

Children with ADHD were recruited from a sample of patients who had been referred to the Instituto Colombiano de Neuropedadogia (Barranquilla, Colombia) by qualified neurologists and who continue to be regularly followed by psychiatrists or neurologists of the institute. They all met DSM IV diagnostic criteria for ADHD (American Psychiatric Association, 2000). The assessment was conducted separately with teachers, children and their parents, and made on the basis of a semi-structured clinical diagnostic interview (DSM IV checklist) by trained neurologists specialized in ADHD. Final diagnoses were reached by a consensus on the basis of the results of structured interviews, collateral historical information, different behavioral scales rated by parents and teachers, and clinical interviews of parents and children by a committee of clinicians, all of whom have extensive experience with ADHD. The Instituto Colombiano de Neuropedadogia is known to the Caribbean community for providing comprehensive diagnostic and psychoeducational services. Moreover, it is approved

\footnotetext{
${ }^{1}$ Colombian neighbourhoods are classified by socio-economic status. All children who participated to the study lived in the 3-4 zone (medium incomings).
} 
Impulse capture and inhibition in ADHD

by the Colombian government as a neuroscience institution conducting developmental and clinical child and adolescent research.

In addition, in order to compare control and ADHD groups, the parents of each child filled out a behavioral rating scale, the EDAH scale (Evaluacion Deficit de Atencion e Hiperactividad, Farré \& Narbona, 2013; Sánchez, Ramos, Díaz \& Simón, 2010).

For this study, only children who had never received medication were contacted and solicited for their participation: even with a $24-48 \mathrm{~h}$ wash out period, it is difficult to exclude the possibility that medication could affect cognitive performance. Three children had comorbid oppositional defiant disorder (ODD).

\subsubsection{Inclusion criteria for the control group}

Children from the non-ADHD group were recruited via local schools in Barranquilla. They all attended normal classes corresponding to their age level. Inclusion criteria were the following: $1 /$ absence of current or previous diagnosis of ADHD determined by completion of the EDAH, 2/ absence of emotional disturbance or learning disabilities based on teachers' and academic psychologists' reports, $3 /$ no concurrent treatment with psychotropic medication.

\subsubsection{Exclusion criteria for both groups}

Exclusion criteria included (1) a diagnosis of any additional psychiatric disorder (major depression, panic disorder, suicide risk, anxiety, substance abuse, psychoactive substance use, psychotic disorders) on the basis of a Spanish version of the structured psychiatric interview (Children's Interview for Psychiatric Syndromes, CHIPS) (Weller, Weller, Fristad, Rooney \& Schecter, 2000) performed by a neurologist before the experiment, (2) absence of consent or parental consent, (3) an intelligence quotient (IQ) $<70$, assessed by the vocabulary-block design short-form of the Wechsler Intelligence Scale for Children. The Spanish version of the 
WISC III (Wechsler, 1991) was used and IQ was calculated with reference to Mexican norms since Colombian norms do not exist. In addition, all participants also performed the working memory index from the WISC III (Spanish version with Mexican norms) (Wechsler, 1991), which comprised arithmetic, digit span, and letter-number sequencing subtests to assess working memory.

\subsection{Simon choice $R T$ task}

Stimuli and apparatus. Participants were comfortably seated facing a black computer screen, located $80 \mathrm{~cm}$ away, upon which stimuli appeared. A plastic board was placed in front of the participant. Two plastic cylinders were fixed on the board and served as handgrips. One pressbutton was fixed to the top of each cylinder. The participant had to maintain the distal phalanxes of each thumb on the response buttons. Responses were given by pressing the top of one of the two cylinders either with the right or left thumb. All stimuli and responses were controlled using components of Psychopy (Peirce, 2007). RTs were recorded to the nearest millisecond.

Task and procedure. Throughout the test, two experimenters were present. One sat near the participant and the other one managed the computer programs. Each trial started with the appearance of a central fixation point that participants had to fixate during the entire trial. After a delay of $500 \mathrm{~ms}$, a picture appeared on either the right or left of the fixation point. Children had to press the left or right button as a function of the presented picture, as quickly and accurately as possible. The stimuli remained on the screen until children responded. Two types of trials were defined: Congruent trials (CG) in which the required response was ipsilateral to the stimulus location, and incongruent trials (IG) in which the required response was contralateral to the stimulus location. 
Impulse capture and inhibition in ADHD

Three different sets of stimuli were used in order to keep the subject engaged in the task (set 1: banana versus carrot; set 2: pig versus frog; set 3: strawberry versus hazelnut) (Smigasiewicz, Ambrosi, Blaye, \& Burle, 2020). Each participant performed the task with the three sets. The set-order and the picture-response mapping (for example, press right for a banana and press left for a carrot) were counterbalanced across participants. For each set, participants performed one training session of 34 trials corresponding to 17 IG trials and 17 CG trials, presented in random order, to familiarize themselves with the task. They then performed four experimental blocks of 25 trials. The first trial of each block was chosen randomly and not further analyzed. The remaining 24 trials corresponded to 12 IG trials and 12 CG trials, presented in random order. To summarize, each child performed three sets of 100 trials each. The sets were separated by a pause of about 5 minutes and the entire experiment lasted about 60 minutes.

\subsection{EMG signal recording and processing}

The EMG activity of the flexor pollicis brevis was recorded bipolarly by means of surface $\mathrm{Ag} /$ $\mathrm{AgCl}$ electrodes, $6 \mathrm{~mm}$ in diameter, fixed about $10 \mathrm{~mm}$ apart on the skin of the thenar eminence. EMG activity was amplified, digitized on-line at $2048 \mathrm{~Hz}$, and offline high-pass filtered at $10 \mathrm{~Hz}$. In order to facilitate off-line EMG onset detection, the EMG signal was continuously monitored by the experimenter to minimize the influence of background activity that could interfere with small bursts of muscular activation during the reaction period. If the signal became noisy, the experimenter immediately asked the child to relax his/her muscles. He also regularly reminded the child to keep hands on the handgrips.

To detect very small incorrect muscular activation, onsets of EMG activity were detected by a home-made custom program written in Python to facilitate visual inspection (this home-made custom Python program, which will soon be released with an open-source 
Impulse capture and inhibition in ADHD

license, is accessible upon request). EMG traces of each participant were then inspected visually and corrected manually in the case of inaccurate detection by the program. The processing of EMG data was performed by an experimenter who was blind to diagnostic group.

\subsection{EMG data analysis}

The analysis of EMG data had two main objectives: (1) classification of responses into three trial types in order to compute incorrect activation rate (IAR) and correction rate (CR), and (2) chronometric analysis of data to decompose RT into decisional and motor subcomponents.

Computation of IAR and CR. First, correct trials were sorted into two categories, labeled "pure correct" and "partial error" trials. "Partial error" trials contained activation of the agonist muscle involved in the incorrect response prior to activation of the agonist involved in the correct response. Importantly, to be classified as a "partial error", EMG signal detection had to be phasic and to return to baseline (rest) before the onset of the response-related EMG activity. Response errors and partial errors were detected and counted and the two variables were then calculated: IAR $=$ (partial errors + overt errors $) /$ total number of non rejected trials, and $\mathrm{CR}=\mathrm{PE} /(\mathrm{PE}+\mathrm{E})$ where $\mathrm{PE}$ is the number of partial errors and $\mathrm{E}$ the number of overt errors.

Chronometric analysis. The EMG analysis also provided access to several different chronometric indices as illustrated in Figure 1. Reaction time (RT) was defined as the latency between stimulus onset and the button press response. It was broken down into two components: premotor time (PMT, from stimulus onset to EMG onset), and motor time (MT, from EMG onset to the button press). For partial error trials, two additional indices were 
defined: Partial error latency (PEL) corresponding to the interval between stimulus onset and EMG onset of the incorrect response, and correction time (CT) corresponding to the latency between incorrect EMG onset and correct EMG onset (Figure 1).

Two-way ANOVAs, with the between-subjects factor of Group (ADHD versus non-ADHD) and the within-subject factor of Congruency (CG versus IG), were performed on the different variables. Proportional scores (error rate, incorrect activation rate, correction rate), in particular when they are rather high (or low), have non-Gaussian distributions because of ceiling (or floor) effects. Therefore, to normalize distributions, data were arcsine transformed before being entered into the ANOVA. This nonlinear but monotonic transformation allows a Gaussian distribution to be obtained so that the required conditions for the ANOVA are met (Winer, 1970).

Cohen's d was used to compute effect size (standardized difference between the two means) for the two group comparisons; effect sizes are commonly classified as small $(d=0.2)$, medium $(d=0.5)$, or large $(d=0.8)($ Cohen, 1988).

\section{Results}

Three children with ADHD and one non-ADHD child were excluded from analyses because their EMG signal was too noisy (participants did not succeed in relaxing their muscles). Analyses were thus performed with data from 23 children with ADHD and 25 non-ADHD children.

\subsection{Demographic and neuropsychological variables}

Differences between demographic characteristics of non-ADHD and ADHD groups were tested using independent sample two-tailed $t$ tests. As shown in Table 1, although there was 
Impulse capture and inhibition in ADHD

no difference in age, children with ADHD had smaller IQ scores and working memory index. Scores on the EDAH were significantly different.

INSERT TABLE 1 ABOUT HERE

\subsection{Simon task}

Extreme RT values, either excessively fast $(<150 \mathrm{~ms}$, so-called anticipatory errors) or slow (> 3 standard deviations [SDs]), were removed from the analysis. On average, this led to the exclusion of fewer than $1 \%$ of trials per participant. In addition, specifically for EMG data, some trials $(2.02 \%)$ were rejected due to tonic activity or artifacts preceding the contraction involved in the response.

\subsubsection{Behavioral data}

Mean Reaction times. As shown in Figure 2A, mean RTs were longer for children with ADHD (617 ms) compared with non-ADHD children (518 ms) ( $F_{1,46}=5.47 ; \mathrm{p}=.02$; Cohen's $d=.66)$, and longer in IG trials $(583 \mathrm{~ms})$ than in CG trials $(549 \mathrm{~ms})\left(\mathrm{F}_{1,46}=97.99 ; \mathrm{p}<.0001\right)$. The difference between groups for the interference effect was medium in magnitude $\left(\right.$ Cohen' $\mathrm{s}^{2} d=.54$; ADHD group $=41 \mathrm{~ms}$, non-ADHD group $\left.=28 \mathrm{~ms}\right)$, but the difference was not statistically significant (Group x Congruency interaction: $F_{1,46}=3.57 ; p=.06$ ).

Intra-subject RT variability. The intra-subject RT variability (SD) was larger in children with $\operatorname{ADHD}(199 \mathrm{~ms})$ compared to non-ADHD children $(113 \mathrm{~ms})\left(\mathrm{F}_{1,46}=12.1 ; \mathrm{p}=.001\right.$; Cohen's $d$ $=.99)$ and larger in CG trials $(156 \mathrm{~ms})$ than in IG trials $(149 \mathrm{~ms})\left(\mathrm{F}_{1,46}=4.8 ; \mathrm{p}=.03\right)$. There was no statistically significant Group x Congruency interaction $\left(\mathrm{F}_{1,46}=2.3 ; \mathrm{p}=.10\right)$.

\footnotetext{
${ }^{2}$ Cohen's $d$ refers to the comparison of interference effects (mean CG RT-mean IG $R T)$ between groups
} 
Impulse capture and inhibition in ADHD

Error rate. As shown in Figure 2B, children with ADHD committed more errors (7.5\%) than non-ADHD children $(3.9 \%)\left(\mathrm{F}_{1,46}=12.8 ; \mathrm{p}<.0001\right.$; Cohen's $\left.d=1.02\right)$. As usual, the error rate was higher in IG trials $(7.7 \%)$ compared to CG trials $(3.5 \%)\left(\mathrm{F}_{1,46}=52.7 ; \mathrm{p}<.0001\right)$. The interference effect was larger in children with ADHD (6\%) compared with non-ADHD children (2.6\%) (Group x Congruency interaction: $\mathrm{F}_{1,46}=8.08 ; \mathrm{p}=.006$; Cohen's ${ }^{3} d=.81$ ). INSERT FIGURE 2 ABOUT HERE

\subsubsection{Analysis from partial errors}

From EMG activity, three categories of trials were determined: pure correct, partial error and real error. The percentage of each trial type for each group is presented in Table 2. The percentage of pure correct trials was lower for ADHD group than for non-ADHD group but children with ADHD did not commit more partial errors than non-ADHD children. INSERT TABLE 2 ABOUT HERE

Incorrect activation rate. The IAR data, combining real errors and partial errors, revealed that children with ADHD made more incorrect EMG activations (19.9\%) than non-ADHD children $(15.2 \%)\left(\mathrm{F}_{1,46}=5.53 ; \mathrm{p}=.023\right.$; Cohen's $\left.d=.69\right)$ (Figure 3A). IAR was larger for IG trials $(23.7 \%)$ than for $\mathrm{CG}$ trials $(11.6 \%)\left(\mathrm{F}_{1,46}=99.73 ; \mathrm{p}<.0001\right)$. The difference between groups for the interference effect was medium in magnitude (Cohen's $d=.53$; ADHD group $=$ $14.4 \%$, non-ADHD group $=9.9 \%$ ) but the difference was not statistically significant (Congruency x Group: $\mathrm{F}_{1,46}=3.44 ; \mathrm{p}=.07$ ).

Even more relevant for our purpose, IAR in IG trials, considered an index of the strength of impulse capture, was larger in children with ADHD (27.4\%) than in non-ADHD children $(20.6 \%)\left(t_{46}=2.62 ; \mathrm{p}=.011 ;\right.$ Cohen's $\left.d=.67\right)$.

\footnotetext{
${ }^{3}$ Cohen's $d$ refers to the comparison of interference effects ( CG accuracy rate - IG accuracy rate) between groups
} 
Impulse capture and inhibition in ADHD

Correction rate. The CR was lower for the ADHD group (60.7\%) than for the non-ADHD group $(73.1 \%)\left(\mathrm{F}_{1,46}=6.84 ; \mathrm{p}=.012 ;\right.$ Cohen's $\left.d=.94\right)($ Figure 3B). There was no significant difference between CG (69.2\%) and IG trials $(65.9 \%)\left(\mathrm{F}_{1,46}=1.35 ; \mathrm{p}=.25\right)$, as classically observed in previous studies (Burle et al, 2002; Burle, Spieser, Servant \& Hasbroucq, 2014). The Group X Congruency interaction was not significant $\left(\mathrm{F}_{1,46}=.9 ; \mathrm{p}=.35\right)$. INSERT FIGURE 3 ABOUT HERE

\subsubsection{Chronometric analysis}

2.2.3.1. Reaction time components in pure correct trials

Premotor times (PMT). Mean PMT was longer for the ADHD group (467 ms) than for the non-ADHD group (399 ms) $\left(\mathrm{F}_{1,46}=4.14 ; \mathrm{p}=.048\right.$; Cohen's $\left.d=.57\right)$ and mean PMT was longer in IG trials $(452 \mathrm{~ms})$ than in CG trials $(414 \mathrm{~ms})\left(\mathrm{F}_{1,46}=71.61 ; \mathrm{p}<.0001\right)$ (Figure 4). The Group x Congruency interaction was statistically significant $\left(\mathrm{F}_{1,46}=5.03 ; \mathrm{p}=.03\right.$; Cohen's $d=.63$ ) revealing that the interference effect was larger in the ADHD group (49 ms) than in the non-ADHD group (28 ms).

In addition, intra-subject PMT variability was larger in children with ADHD (175 ms) than non-ADHD children $(103 \mathrm{~ms})\left(\mathrm{F}_{1,46}=10.65 ; \mathrm{p}=.002\right.$; Cohen's $\left.d=.92\right)$, but intra-subject PMT variability was no different between $C G$ and IG trials $\left(\mathrm{F}_{1,46}=.35 ; \mathrm{p}=.55\right)$. The difference in variability between IG and CG trials was significantly larger in children with ADHD (14 ms) than in non-ADHD children ( $9 \mathrm{~ms})$, as indicated by the significant Group $\mathrm{x}$ Congruency interaction $\left(\mathrm{F}_{1,46}=7.81 ; \mathrm{p}=.007\right.$; Cohen's $\left.d=.78\right)$.

Motor times $(M T)$. For mean MT, there was no difference between groups $\left(\mathrm{F}_{1,46}=.77 ; \mathrm{p}=\right.$ $.38)$, no difference between $\mathrm{CG}$ and IG trials $\left(\mathrm{F}_{1,46}=2.52 ; \mathrm{p}=.12\right)$ replicating previous results 
Impulse capture and inhibition in ADHD

(Burle et al, 2002; Burle, Spieser, Servant, \& Hasbroucq, 2014), and no Group X Congruency interaction $\left(\mathrm{F}_{1,46}=.01 ; \mathrm{p}=.92\right)($ Figure 4$)$. Concerning intra-subject MT variability, there was no difference between groups $\left(\mathrm{F}_{1,46}=.23 ; \mathrm{p}=.63\right)$, nor between $\mathrm{CG}$ and IG trials $\left(\mathrm{F}_{1,46}=.1 ; \mathrm{p}\right.$ $=.75)$. There was no significant Group $x$ Congruency interaction $\left(\mathrm{F}_{1,46}=.007 ; \mathrm{p}=.93\right)$. INSERT FIGURE 4 ABOUT HERE

\subsubsection{PMT components in partial error trials}

Partial error latency (PEL). Mean PEL was longer for the ADHD group (340 ms) than for the non-ADHD group (291 ms) ( $\mathrm{F}_{1,46}=4.67 ; \mathrm{p}=.036$; Cohen's $\left.d=.59\right)$ (Figure 5A). It was longer for CG (332 ms) than for IG trials $(307 \mathrm{~ms})\left(\mathrm{F}_{1,46}=5.47 ; \mathrm{p}=.023\right)$, as is typically observed (Burle et al, 2002; Burle, Spieser, Servant, \& Hasbroucq, 2014). The Group x Congruency interaction was not significant $\left(\mathrm{F}_{1,46}=.41 ; \mathrm{p}=.53\right)$. In addition, intra-subject PEL variability was larger in children with ADHD (141 ms) than in non-ADHD children (93 ms) $\left(\mathrm{F}_{1,46}=6.73 ; \mathrm{p}=.01\right.$; Cohen's $\left.d=.65\right)$ and larger in CG trials $(127 \mathrm{~ms})$ than in IG trials $(100 \mathrm{~ms})\left(\mathrm{F}_{1,46}=4.31 ; \mathrm{p}=.04\right)$. There was no significant Group $\mathrm{x}$ Congruency interaction $\left(\mathrm{F}_{1,46}=.22 ; \mathrm{p}=.64\right)$ for intra-subject PEL variability

Correction time $(C T)$. The difference between groups was medium in magnitude (Cohen's $d=$ .45; ADHD group: $312 \mathrm{~ms}$; non-ADHD group: $280 \mathrm{~ms}$ ) but the difference was not statistically significant $\left(\mathrm{F}_{1,46}=3.04 ; \mathrm{p}=.088\right)($ Figure $5 \mathrm{~B}) . \mathrm{CT}$ was not affected by congruency $\left(\mathrm{F}_{1,46}=\right.$ $.02 ; \mathrm{p}=.89)$ and there was no significant Group $\mathrm{x}$ Congruency interaction $\left(\mathrm{F}_{1,46}=.74 ; \mathrm{p}=\right.$ .39). Moreover, intra-subject $\mathrm{CT}$ variability was no different between groups $\left(\mathrm{F}_{1,46}=2.46 ; \mathrm{p}=\right.$ $.13)$, nor between $\mathrm{CG}$ and IG trials $\left(\mathrm{F}_{1,46}=2.56 ; \mathrm{p}=.12\right)$ but there was a significant Group $\mathrm{x}$ Congruency interaction $\left(\mathrm{F}_{1,46}=3.91 ; \mathrm{p}=.05\right)$. INSERT FIGURE 5 ABOUT HERE 


\subsection{Correlation analyses}

Correlation coefficients were computed between our two indices of interest (IAR and CR) and working memory indices and IQ, for each group. No statistically significant correlations were found (see Table 3).

INSERT TABLE 3 ABOUT HERE

\section{Discussion}

The aim of the present study was to investigate interference control in children with ADHD when performing a Simon task. Using EMG activity recordings, we were able to distinguish two components of interference control and so separately evaluate the intensity of impulse capture and the ability to inhibit automatic responses.

\subsection{Children with ADHD have impaired behavioral performance in conflict tasks}

A traditional analysis of RTs and error rates revealed two main results. Firstly, we observed greater intra-individual RT variability in children with ADHD compared to nonADHD children. This is consistent with data found in prior studies, which report increased intra-individual RT variability in a variety of different RT tasks (Klein, Wendling, Huettner, Ruder \& Peper, 2006; Lipszyc \& Schachtar, 2010; Tamm, Nakonezny \& Hughes, 2012). Nonetheless, it remains open to debate whether this result is ubiquitous and so could represent a stable trait of ADHD, or whether it might also be characteristic of other populations, (Klein, Wendling, Huettner, Ruder \& Peper, 2006; Tamm, Nakonezny \& Hughes, 2012; for review, Kofler et al., 2013). At a cognitive level, the high intra-individual RT variability of patients with ADHD likely reflects impairments in information processing and difficulties in maintaining attentional control. However, the nature of mechanisms and processes responsible for increased RT variability seems not yet clearly identified (for review, see 
Impulse capture and inhibition in ADHD

Kofler et al., 2013; Kofler et al., 2014; Sonuga-Barke \& Castellanos, 2007; Tamm, Nakonezny \& Hughes, 2012).

Secondly, children with ADHD were slower, committed more errors than non-ADHD children, and exhibited a larger interference effect, which suggests that children with ADHD were globally impaired on the Simon RT task compared to non-ADHD children. These data confirm the results of other studies in the literature (Cao et al., 2013; Homack \& Riccio, 2004; Jonkman, et al, 1999; Tsal, Shalev, \& Mevorach, 2005; for a review, see Mullane, Corkum, Klein, \& McLaughlin, 2009) indicating that these children have difficulties in performing conflict tasks. The larger interference effect could arise from difficulties in ignoring the irrelevant feature of the stimulus, its position, and/or in maintaining attention on the relevant feature, its color. In most studies, a larger interference effect is interpreted as being due to poor inhibition (Barkley, 1997; Nigg, 2001). However, the difficulties of children with ADHD could have at least two causes: stronger impulse capture, that is a stronger propensity to activate automatic responses or, alternatively, poorer inhibition of these automatic responses. Analysis of EMG recordings, which allows these two processes to be dissociated, is a convenient way to tackle this issue.

\subsection{What can we learn from partial errors?}

As mentioned in the Introduction, analysis of EMG activity allows us to dissociate two types of trials embedded within correct response trials, pure correct responses and partial errors, and then to compute two indices: incorrect activation rate (IAR) and correction rate (CR). The first index (IAR) expresses all incorrect activations, whether they resulted in an incorrect response or not (if they were corrected) and can be considered an index of the strength of impulse capture, particularly in incongruent (IG) trials in which stimulus position automatically activates the ipsilateral response. The second index (CR) indicates the 
Impulse capture and inhibition in ADHD

proportion of incorrect activations that were corrected before making an overt error and can be considered an index of the efficiency of automatic response inhibition.

Our results revealed a larger IAR in children with ADHD than in non-ADHD children and, more specifically, we observed a larger IAR in IG trials. This indicates that children with ADHD are more likely to automatically activate the response ipsilateral to stimulus position. In other words, they have more difficulty not being influenced by salient yet irrelevant information. Consequently, these children would be more prone to selecting the response that corresponds to the most frequent association between the location of the stimulus and the response, that is, the ipsilateral response. In addition, we observed a lower correction rate in children with ADHD. This second result suggests that children with ADHD had more difficulty stopping and correcting automatic, but erroneous, activations than non-ADHD children. Since incorrect activations were detected and stopped less often, these children committed more overt errors, which contributed to an increased IAR. Therefore, these data provide new and more direct evidence in favor of inhibition deficits in children with ADHD.

Response inhibition includes a variety of processes, such as inhibiting prepotent responses, inhibiting all ongoing responses (global inhibition) and selective inhibition (in interference control tasks). The ability to inhibit prepotent and ongoing responses, as assessed by the stop task, have been extensively studied in ADHD. Most studies report decreased performance in children with ADHD than in their typically developing peers and some authors have concluded that children with ADHD have deficient inhibitory control (for reviews, see Barkley, 1997; Crosbie et al., 2013; Matzke, Verbruggen \& Logan, 2018; Nigg, 2001; Osterlaan, Logan, \& Sergeant, 1998; Sergeant, Geurts, \& Oosterlaan, 2002).

Nonetheless, others who dissected the stop-signal reaction time (SSRT) have proposed that the data reveal an underlying attentional deficit rather than deficient inhibitory control (Alderson, Rapport, \& Kofler, 2007; Alderson, Rapport, Sarver, \& Kofler, 2008; Lijffijt, 
Impulse capture and inhibition in ADHD

Kenemans, Verbaten, \& van Engeland, 2005). However, the authors also concluded that the data do not rule out the possibility that other aspects of inhibitory control, such as interference control could be deficient in ADHD. Indeed, even though global inhibition is at play in the stop-task, selective inhibition (stopping the incorrect response and continuing to execute the correct one) is required in conflict tasks that require interference control, such as the Simon task used here. These two types of inhibition have been shown to partially differ in terms of neural mechanisms and substrates (Aron \& Verbruggen, 2008; Aron, 2011). Our findings therefore suggest that selective inhibition is impaired in ADHD. Inhibition can be used to refer to a variety of different processes and it seems important to more precisely identify which one is impaired in ADHD. Accordingly, Weigard and collaborators (2019) used a Bayesian parametric approach for estimating stop-signal RT distribution in order to better identify the cognitive processes responsible for impaired performance in children with ADHD in stop-tasks. They established that difficulty in stopping a prepotent response was mainly due to a failure to trigger the inhibition process rather than an impairment in the inhibition process itself (Weigard, Heathcote, Matzke, \& Huang-Pollock, 2019). In our study, the correction rate directly reflects the proportion of incorrect activations that have been stopped and corrected or, in other words, successful inhibition via the action cancellation subcomponent of interference control. A decrease in correction rate, as observed in the ADHD group, may indicate failure to trigger the inhibition process as proposed in Weigard et al's study (2019). Impairments in children with ADHD could then be more precisely explained by a difficulty in initiating inhibition rather than by a difficulty in inhibiting the response.

Moreover, impulsive responses entail at least two processes: an impulse or urge to act, whose strength depends on the context, and a lack of inhibition (DeYoung, 2013). Our data suggest that the difficulties observed in conflict tasks in children with ADHD are also explained by a greater propensity to activate automatic responses (as revealed by increased 
Impulse capture and inhibition in ADHD

incorrect activation rate), which is rarely considered in most studies. Our results are partially consistent with those presented in one another behavioral study that investigates both activation and suppression of impulse capture in children with ADHD engaged in a conflict task (Ridderinkhof, Scheres, Oosterlan \& Sergeant, 2005). The authors reported that children with ADHD had difficulty in suppressing automatic response but did not make more impulsive responses in the first place. However, at least two differences with our own experiment may be noted. First, Ridderinkhof et al (2005) used dynamic analysis of performance (delta-plot analysis of reaction times and accuracy) to dissociate the two complementary components of interference, whereas we based our conclusions on indices derived from EMG data, which give more direct access to the activation and suppression of response impulses (Van den Wildenberg et al., 2010). Second, children in the previous study performed a flanker task in which the nature of interference (perceptive interference) is different to that in the Simon task (motor interference). Data from a recent study comparing the two tasks have suggested that the control of inappropriate responses is more difficult to demonstrate, and less stable, in the flanker task (Burle, Spieser, Servant, \& Hasbroucq, 2014).

From a neurobiological point of view, it is interesting to note that some brain structures found to be dysfunctional in ADHD are also involved in interference control. Indeed, anatomical and functional observations converge to indicate that ADHD is associated with a dysfunction of the prefrontal cortex and its connections, in particular with basal ganglia (Dickstein, Bannon, Castellanos \& Milham, 2006; Durston, Van Belle \& De Zeeuw, 2011; Konrad \& Eickhoff, 2010), cerebral structures that are also known to be involved in interference control (Chambers, Garavan \& Bellgroce, 2009; Fassbender \& Schweitzer, 2006; Forstmann, Van den Wildenberg \& Ridderinkhof, 2008; Spieser, van den Wildenberg, Hasbroucq, Ridderinkhof, \& Burle, 2015). More specifically, it has been shown that during tasks requiring interference control, children and adolescents with ADHD show 
Impulse capture and inhibition in ADHD

hypoactivation primarily of inferior frontal cortex (IFC), dorsolateral prefrontal cortex (DLPFC), anterior cingulate cortex (ACC) and caudate nucleus (Bush et al., 1999; Cubillo, Halari, Giampietro, Taylor \& Rubia, 2011; Cubillo, Halari, Smith, Taylor \& Rubia, 2012 ; Rubia et al., 2009; Rubia et al., 2010; Vaidya et al., 2005). Our results might therefore represent the behavioral outcome of functional alterations in structures known to be involved in interference control and which are impaired in individuals with ADHD.

To summarize, our data suggest that the difficulty experienced by children with ADHD in tasks requiring interference control could be explained by both stronger impulse capture and impaired inhibition, two independent processes that can be differentially impaired in certain cases (Fluchère et al., 2015; 2018; Ramdani et al., 2015). For example, subthalamic nucleus stimulation delivered to patients with Parkinson's disease selectively impairs suppression of response impulsivity but does not increase the strength of impulse capture (Fluchère et al., 2018). These two functions are probably anatomically dissociated and this dissociation could have important implications not only for refining explanations of ADHD but also for classifying patients according to different symptoms and determining suitable treatments.

\subsection{What do chronometric indices reveal?}

EMG activity analysis also provided several different chronometric indices, such as premotor time $(\mathrm{PMT})$ and motor time $(\mathrm{MT})(\mathrm{PMT}+\mathrm{MT}=\mathrm{RT})$. We observed slower and more variable PMT for children with ADHD than for non-ADHD children, whereas no difference was found for the mean or variability of MTs between groups. These results confirm that the slowed RTs observed in children with ADHD was not due to motor slowing, therefore arguing against an explanation in terms of motor execution deficits. In contrast, they suggest that RT slowing was instead due to a central decisional deficit, that is, at the level of response selection and 
Impulse capture and inhibition in ADHD

preparation. This is in line with data from the modeling literature. According to computational modeling (such as drift-diffusion model, DDM, Ratcliff \& McKoon, 2008; linear ballistic accumulation model, LBA, Brown \& Heathcote, 2008) accuracy and response time distributions depend on decision and non-decision parameters. Non-decision parameters represent extra-decisional components, such as encoding and motor processes. Among them, one important variable is the drift rate, which reflects task difficulty or information processing ability. It corresponds to the speed with which the accumulation of evidence approaches the response boundary. High drift rates correspond to faster and more accurate responses. A second variable is the boundary separation, which describes the amount of accumulated evidence needed until a decision is made (also called the decision threshold). The majority of studies have found reduced drift in ADHD (Huang-Pollock et al., 2017; Metin et al., 2013; Weigard \& Huang-Pollock, 2014; for a review, see Ziegler, Pedersen, Movinckel, \& Biele, 2016) whereas effects on decision threshold are unclear (Ziegler, Pedersen, Movinckel, \& Biele, 2016). In addition, residual non-decision time is very often reported to be unaffected (Ziegler, Pedersen, Movinckel, \& Biele, 2016) though not always (Metin et al., 2013). Nondecision time includes both perceptual and motor times. In an EMG decomposition of RT, MT can indisputably be linked to motor execution meaning our results are consistent with data from modeling studies. However, PMT comprises both encoding and decision times. Assuming that encoding time is similar in ADHD and non-ADHD groups (as suggested by modeling data), the lengthening of PMT would reflect a lower drift rate. It has to be noted however that standard models (DDM or LBA) cannot correctly fit data from tasks such as Simon, Stroop or Eriksen flanker tasks (Hübner, Steinhauser, \& Lehle, 2010; White, Ratcliff, $\&$ Starns, 2011) because non-constant drift rate models are required to fit conflict data (White, Servant, \& Logan, 2018) and, to the best of our knowledge, such models have not yet been developed. 
Impulse capture and inhibition in ADHD

EMG activity analysis also provided chronometric indices specific to partial error trials, such as partial error latency and correction time. We observed larger and more variable partial error latencies in the ADHD group compared to the non-ADHD group, suggesting that children with ADHD were slower than non-ADHD children even when committing a partial error, that is, when an incorrect activation had been triggered. They also tended to be slower to correct these erroneous activations, suggesting that all processes, correct or incorrect, are delayed in children with ADHD. This delay, observed at each stage of processing, again speaks in favor of fluctuations in sustained attention.

Interestingly, these results appear to be in line with the recent neuro-energetic theory (NeT) of ADHD (Killeen, Russell \& Sergeant, 2013; Killeen, 2013), which proposes that an insufficient neuronal energy supply, due to a deficit in lactate supplementation, could impair all forms of effortful responses. Impairment at any point in the neurobiological cascade of lactate synthesis would produce neuronal fatigue, which in turn would cause fluctuations in sustained attention. Lapses of attention could cause children with ADHD to have difficulty in focusing their attention on the relevant stimulus feature, since non-salient task-dependent features require controlled attention. These children would then be more prone to initiating automatic location-driven responses. Moreover, some studies suggest that suppressing automatic responses may be under top-down control and depend upon attentional resources (Suarez, Vidal, Burle \& Casini, 2015). Inattention and difficulties in cognitive control may therefore be linked (Alderson, Rapport, \& Kofler, 2007; Weigard, Heathcote, Matzke, \& Huang-Pollock, 2019).

\subsection{Limitations and conclusion}

There are at least two limitations to the current study. The first limitation refers to the existence of a between-group difference in IQ and WMI, though this is not unique to the 
Impulse capture and inhibition in ADHD

present study. More intriguing is that both groups and particularly the non-ADHD group had relatively high IQ scores and WMI compared to other studies. But, as mentioned in the Methods section, IQ scores and WMI were evaluated with the Spanish version of the WISC III using Mexican norms because Colombian norms are not available. It is therefore possible that IQ scores and WMI were overestimated for both groups compared with studies using more recent versions of the WISC and norms developed in the country where studies were conducted. Nonetheless, the difference in IQ raises a question as to whether our results would persist after controlling for IQ. However, it has to be noted that IQ was used only as an inclusion criterion and was evaluated by only two sub-tests of the WISC. Moreover, we believe that IQ should not be included as a covariate in cognitive studies for at least two reasons: 1/IQ measures aptitude and potential, rather than performance; 2/IQ does not fulfill the methodological and statistical requirements of a covariate (for detailed arguments, see Dennis et al., 2009). In addition, even though some studies indicate a mediating effect of IQ on inhibition (Mahone et al., 2002), others have shown that not all executive functions, particularly inhibition, are related to IQ (Friedman et al., 2006, Bitsakou et al., 2008). Similarly, it has also been proposed that WMI and inhibitory processes could be related (Miyake et al., 2000; Karr et al., 2018). It might then be hypothesized that the superior working memory of the non-ADHD group could have artificially inflated estimates of an inhibition deficit in ADHD. We observed no statistically significant correlation between WMI and correction rate in either group (Table 3). However, due to our sample size, correlations suggest a modest relationship between WMI and correction rate for the non-ADHD group. A last point that can be mentioned is that studies investigating potential relationships between inhibition and IQ or WMI present at least three noticeable differences with the present study: 1/ a full-scale IQ test is usually used, not simply two subtests of the WISC; 2/ cognitive working memory tasks are used, not only subtests of the WISC; 3/ a variety of inhibitory tasks 
Impulse capture and inhibition in ADHD

or neuropsychological tests are used to measure inhibition but no study has yet used a variable as precise and directly linked to inhibitory processes as the correction rate. Nonetheless, our data merit confirmation in future studies in which both groups of children would be matched in age, gender, WMI and IQ scores. In this regard, we would like to mention that we carried out a sensitivity analysis that compared two groups matched for IQ and WMI scores (nonADHD children with very high scores were excluded) and that the findings were very comparable to those reported in the present manuscript. Data are available in Supplementary Materials (Table S1).

The second limitation refers to the fact that because ADHD is so heterogeneous, further studies are needed to fully understand this developmental disorder. For example, the question of whether ADHD is due to a central deficit or to multiple deficits, as proposed more and more frequently (Castellanos \& Tannock, 2002; Castellanos, Sonuga-Barke, Milham, \& Tannock, 2006; Nigg, Willcutt, Doyle \& Sonuga-Barke, 2005), should be a crucial question in developing further studies. Comparing the performance of a group of predominantly inattentive children with a group of predominantly hyperactive children using EMG activity and the indices described here would be of great interest.

To conclude, our data suggest that the deficit in interference control in children with ADHD can be explained by both stronger impulse capture and difficulty in inhibiting such impulses, which are two independent processes. Moreover, the slowing of all processes along the sensorimotor chain suggests difficulties in sustained attention, which could also exacerbate difficulties in interference control. One interesting follow-up to the current study could be to evaluate how different treatments, such as stimulant medication or behavioral therapy, separately affect impulse capture and inhibitory control. Although children with ADHD demonstrated impairment in both processes, it is possible that treatments differentially 
Impulse capture and inhibition in ADHD

affect one of the two processes, which could shed light on the heterogeneity of treatment response. 


\section{References}

Alderson, R.M., Rapport, M.D., \& Kofler, M.J. (2007). Attention-deficit/hyperactivity disorder and behavioral inhibition: a meta-analytic review of the stop-signal paradigm. Journal of Abnormal Child Psychology, 35, 745-758.

Alderson, R.M., Rapport, M.D., Sarver, D.E., \& Kofler, M.J. (2008). ADHD and behavioral inhibition: A re-examination of the Stop-signal task. Journal of Abnormal Child Psychology, 36, 989-998.

American Psychiatric Association. (2000). Diagnostic and statistical manual of mental disorders. Forth Edition Revised (DSM IV-TR). Washington DC.

Aron, A.R. (2011). From reactive to proactive and selective control: developing a richer model for stopping inappropriate responses. Biological Psychiatry. 69(12): e55-e68.

Aron, A.R., \& Verbruggen, F. (2008). Stop the presses: dissociating a selective from a global mechanism for stopping. Psychological Science, 19, 1146-1153.

Barkley, R.R. (1997). Behavioral inhibition, sustained attention, and executive functions: constructing a unifying theory of ADHD. Psychological Bulletin, 121, 65-94.

Bitsakou, P., Psychogiou, L., Thompson, M., \& Sonuga-Barke, E.J.S. (2008). Inhibitory deficits in attention-deficit/hyperactivity disorder are independent of basic processing efficiency and IQ. Journal of Neural Transmission, 115, 261-268. 
Borella, E., de Ribaupierre, A., Cornoldi, C., \& Chicherio, C. (2013). Beyond interference control impairment in ADHD: Evidence from increased intraindividual variability in the color-stroop test. Child Neuropsychology, 19(5), 495-515.

Brown, S.D., \& Heathcote, A. (2008). The simplest complete model of choice response time: Linear ballistic accumulation. Cognitive Psychology, 57,153-178.

Burle, B., Possamaï, C.A., Vidal, F., Bonnet, M., \& Hasbroucq, T. (2002). Executive control in Simon effect: an electromyographic ans distributional analysis. Psychological Research, 66, 324-336.

Burle, B., Spieser, L., Servant, M., \& Hasbroucq, T. (2014). Distributional reaction time properties in the Eriksen task: marked differences or hidden similarities with the Simon task? Psychonomic Bulletin and Review, 21, 1003-1010.

Bush, G., Frazier, J. A., Rauch, S. L., Seidman, L. J., Whalen, P. J., Jenike, M. A., Rosen, B.R., \& Biederman, J. (1999). Anterior cingulate cortex dysfunction in attentiondeficit/hyperactivity disorder revealed by fMRI and the counting stroop. Biological Psychiatry, 45, 1542-1552.

Cao, J., Wang, S., Ren, Y., Zhang, Y., Cai, J., Tu, W., Shen, H., Dong, X., \& Xia, Y. (2013). Interference control in 6-11 year-old children with and without ADHD: behavioral and ERP study. International Journal of Developmental Neuroscience, 31, 342-349. 
Impulse capture and inhibition in ADHD

Castellanos, F.X., \& Tannock, R. (2002). Neuroscience of attention-deficit/hyperactivity disorder: the search for endophenotypes. Nature Reviews Neuroscience, 3, 617-628.

Castellanos, F.X., Sonuga-Barke, E.J.S., Milham, M.P \& Tannock, R. (2006). Characterizing cognition in ADHD: beyond executive dysfunction. Trends in Cognitive Sciences, 10, $117-$ 123.

Chambers, C.D., Garavan, H., \& Bellgroce, M.A. (2009). Insights into the neural basis of response inhibition from cognitive and clinical neuroscience. Neuroscience and Biobehavioral Reviews, 33, 631-646.

Coghill, D.R., Seth, S., \& Matthews, K. (2014). A comprehensive assessment of memory, delay aversion, timing, inhibition, decision making and variability in attention deficit hyperactivity disorder: advancing beyond the three-pathway models. Psychological Medicine, 44(9), 1-13.

Cohen, J. (1988). Statistical power analysis for the behavioral sciences (2nd ed.). Hillsdale, NJ: Lawrence Earlbaum Associates.

Crosbie, J., Arnold, P., Paterson, A., Swanson, J., Dupuis, A., Li, X., Shan, J., Goodal, T., Strug, L, \& Schachar, R.J. (2013). Response inhibition and ADHD traits: correlates and heritability in a community sample. Journal of Abnormal Child Psychology, 41, 497-507.

Cubillo, A., Halari, R., Giampietro, V., Taylor, E., \& Rubia, K. (2011). Fronto-striatal underactivation during interference inhibition and attention allocation in grown up children 
Impulse capture and inhibition in ADHD

with attention deficit/hyperactivity disorder and persistent symptoms. Psychiatry Research: Neuroimaging, 193, 17-27.

Cubillo, A., Halari, R., Smith, A., Taylor, E., \& Rubia, K. (2012). A review of fronto-striatal and fronto-cortical brain abnormalities in children and adults with Attention Deficit Hyperactivity Disorder (ADHD) and new evidence for dysfunction in adults with ADHD during motivation and attention. Cortex, 48, 194-215.

De Jong, R., Liang, C-C., \& Lauber, E. (1994). Conditional and Unconditional Automaticity: A Dual-Process Model of Effects of Spatial Stimulus-Response Correspondence. Journal of Experimental Psychology: Human Perception and Performance, 20, 731-750.

Dennis, M., Francis, D.J., Cirino, P.T., Schachar, R., Barnes, M.A., \& Fletcher, J.M. (2009). Why IQ is not a covariate in cognitive studies of neurodevelopmental disorders. Journal of the International Neuropsychological Society, 15, 331-343.

DeYoung, C. (2013). The neuromodulator of exploration: A unifying theory of the role of dopamine in personality. Frontiers in Human Neuroscience. doi: 10.3389/fnhum.2013.00762

Dickstein, S.G., Bannon, K., Castellanos, X., \& Milham, M.P. (2006). The neural correlates of attention deficit hyperacticity disorder: an ALE meta-analysis. Journal of Child Psychology and Psychiatry, 47, 1051-1062. 
Durston, S., Van Belle, J., \& De Zeeuw, P. (2011). Differenciating frontostriatal and frontocerebellar circuits in attention-deficit/hyperactivity disorder. Biological Psychiatry, 69, 11781184.

Eriksen, C. W., Coles, M. G., Morris, L. R., \& O'Hara, W. P. (1985). An electromyographic examination of response competition. Bulletin of the Psychonomic Society, 23, 165-168.

Eriksen, B. A., \& Eriksen, C. W. (1974). Effects of noise letters upon the identification of a target letter in a nonsearch task. Attention, Perception, \& Psychophysics, 16, 143-149.

Farré A., \& Narbona, J. (1998). EDAH. Escalas para la evaluación del trastorno por déficit de atención con hiperactividad. (TEA). Madrid.

Fassbender, C., \& Schweitzer, J.B. (2006). Is there evidence for neural compensation in attention deficit hyperactivity disorder? A review of the functional neuroimaging literature. Clinical Psychology Review, 26, 445-465.

Fluchere, F., Deveaux, M., Burle, B., Vidal, F., van den Wildenberg, W.P.M., Witjas, T., Eusebio, A. Azulay, J.P., Hasbroucq, T. (2015). Dopa therapy and action impulsivity: subthreshold error activation and suppression in Parkinson's disease. Psychopharmacology, 232, $1735-1746$.

Fluchere, F., Burle, B., Vidal, F., van den Wilbenberg, W.P.M., Witjas, T., Eusebio, A., Azulay, J.P., Hasbroucq, T. (2018). Subthalamic nucleus stimulation, dopaminergic treatment and impulsivity in Parkinson's disease. Neuropsychologia, 117, 167-177. 
Forstmann, B.U., Van den Wildenberg, W.P.M., \& Ridderinkhof, K.R. (2008). Neural mechanisms, temporal dynamics, and individual differences in interference control. Journal of Cognitive Neuroscience, 20, 1854-1865.

Friedman, N. P., Miyake, A., Corley, R. P., Young, S. E., De Fries, J. C., \& Hewitt, J. K. (2006). Not all executive functions are related to intelligence. Psychological Science, 17(2), $172-179$.

Hasbroucq, T., Possamaï, C.A., Bonnet, M., \& Vidal, F. (1999). Effect of irrelevant location of the response signal on choice reaction time: an electromyographic study in humans. Psychophysiology, 36, 522-526.

Hasbroucq, T., Burle, B., Akamatsu, M., Vidal, F., \& Possamaï, C.A. (2001). An electromyographic investigation of the effect of stimulus-response mapping on choice reaction time. Psychophysiology, 38, 157-162

Hasbroucq, T., Burle, B., Vidal, F., \& Possamaï, CA. (2009). Stimulus-hand correspondence and direct response activation: An electromyographic analysis. Psychophysiology, 46, 11601169.

Homack, S., \& Riccio, C.A. (2004). A meta-analysis of the sensitivity and specificity of the Stroop color and word test with children. Archives of Clinical Neuropsychology, 19, 725 743.The $S$ 
Hommel, B. (2011). The Simon effect as tool and heuristic. Acta Psychologica, 136, 189-202.

Huang-Pollock, C., Ratcliff, R., McKoon, G., Shapiro, Z., Weigard, A., \& Galloway-Long, H. (2017).Using the diffusion model to explain cognitive deficits in attention deficit hyperactivity disorder. Journal of Abnormal Psychology, 45, 57-68.

Hübner, R., Steinhauser, M., \& Lehle, C. (2010). A dual-stage two-phase model of selective attention. Psychological Review, 117(3), 759-784.

Jonkman, L.M., Kemner, C., Verbaten, M.N., Van Engeland, H., Kenemans, J.L., Gamfferman, G., Buitelaar, J.K., \& Koelega, H.S. (1999). Perceptual and response interference in children with attention-deficit hyperactivity disorder, and the effects of methylphenidate. Psychophysiology, 36, 419-429.

Karr, J., Areshenkoff, C., Rast, P., Hofer, S., Iverson, G., \& Garcia-Barrera, M. (2018). The unity and diversity of executive functions: A systematic review and re-analysis of latent variable studies. Psychological bulletin, 144(11), 1147-1185.

Killeen, P.R. (2013). Absent without leave; a neuroenergetic theory of mind wandering. Frontiers in Psychology, 4.

Killeen, P.R., Russell, V.A., \& Sergeant, J.A. (2013). A behavioral neuroenergetics theory of ADHD. Neuroscience and Biobehavioral Reviews, 37, 625-657. 
Impulse capture and inhibition in ADHD

Klein, C., Wendling, K., Huettner, P., Ruder, H., \& Peper, M. (2006). Intrasubject variability in attention-deficit hyperactivity disorder. Biological Psychiatry, 60, 1088-1097.

Kofler, M.J., Rapport, M.D., Sarver, D.E., Raiker, J.S., Orban, S.A., Friedman, L.M., \& Kolomeyer, E.G. (2013). Reaction time variability in ADHD: A meta-analytic review of 319 studies. Clinical Psychology Review, 33, 795-811.

Kofler, M.J., Alderson, R.M., Raiker, J.S., Bolden, J., Sarver, D.E., Rapport, M.D. (2014). Working memory and intra-individual variability as neurocognitive indicators in ADHD: examining competing model predictions. Neuropsychology, 28, 459-471.

Konrad, K., \& Eickhoff, S.B. (2010). Is the ADHD Brain Wired Differently? A Review on Structural and Functional Connectivity in Attention Deficit Hyperactivity Disorder. Human Brain Mapping, 31, 904-916.

Kornblum, S., Hasbroucq, T., \& Osman, A. (1990). Dimensional Overlap: cognitive basis for stimulus-response compatibility-a model and taxonomy. Psychological Review, 97, 253-270.

Kornblum, S., (1994). The way irrelevant dimensions are processed depends on what they overlap with: The case of Stroop- and Simon-like stimuli. Psychological Research, 56, 130135.

Lijffijt, M., Kenemans, L., Verbaten, M. N., \& van Engeland, H. (2005). A meta-analytic review of stopping performance in attention-deficit/hyperactivity disorder: deficient inhibitory motor control? Journal of Abnormal Psychology, 114, 216-222. 
Lipszyc, J., \& Schachtar, R. (2010). Inhibitory control and psychopathology: A meta-analysis of studies using the stop signal task. Journal of the International Neuropsychological Society, $16,1064-1076$.

Lu, C., \& Proctor, R. W. (1995). The influence of irrelevant location information on performance: A review of the Simon and spatial Stroop effects. Psychonomic Bulletin \& Review, 2, 174-207.

Mahone, E.M., Hagelthorn, K.M., Cutting, L.E., Schuerholz, L.J., Pelletier, S.F., Rawlins, C., Singer, H.S., \& Denckla, M.B. (2002). Effects of IQ on executive functions measures in children with ADHD. Child Neuropsychology, 8:1, 52-65.

Matzke, D., Verbruggen, F., \& Logan, G. (2018). The stop signal paradigm. In J.T. Wixted \& E.J. Wagenmakers (Eds.), Stevens' handbook of experimental psychology and cognitive neuroscience (pp. 383-427). Hoboken, NJ: John Wiley \& Sons, Inc.

Metin, B., Roeyers, H., Wiersema, J.R., van der Meere, J.J., Thompson, M., Sonuga-Barke, E. (2013). ADHD performance reflects inefficient but not impulsive information processing: a diffusion model analysis. Neuropsychology, 27, 193-200.

Miyake, A., Friedman, N.P., Emerson, M.J., Witzki, A.H., Howerter, A., \& Wager, T.D., (2000). The unity and diversity of executive functions and their contributions to complex “Frontal Lobe' tasks: A latent variable analysis. Cognitive Psychology 41, 49-100. 
Impulse capture and inhibition in ADHD

Mullane, J.C., Corkum, P.V., Klein, R.M., \& McLaughlin, E. (2009). Interference control in children with ADHD: A systematic review of flanker and Simon task performance. Child Neuropsychology, 15, 321-342.

Nigg, J.T. (2001). Is ADHD a disinhibitory disorder? Psychological Bulletin, 127, 571-598.

Nigg, J.T., Willcutt, E.G., Doyle, A.E. \& Sonuga-Barke, E.J.S. (2005). Causal heterogeneity in Attention-Deficit/Hyperactivity disorder: do we need neuropsychologically impaired subtypes? Biological Psychiatry, 57, 1224-1230.

Oosterlaan, J., Logan, G. D., \& Sergeant, J. A. (1998). Response inhibition in AD/HD, CD, comorbid $\mathrm{AD} / \mathrm{HD}+\mathrm{CD}$, anxious, and control children: A meta-analysis of studies with the stop task. Journal of Child Psychology and Psychiatry, 39, 411-425.

Peirce, J.W. (2007). PsychoPy-Psychophysics software in Python. Journal of Neuroscience Methods, 162, 8-13.

Ramdani, C., Carbonnell, L., Vidal, F., Béranger, C., Dagher, A., Hasbroucq, T. (2015).

Dopamine precursors depletion impairs impulse control in healthy volunteers. Psychopharmacology, 232, 477-487.

Ratcliff, R., \& McKoon, G. (2008). The diffusion decision model: theory and data for twochoice decision tasks. Neural Computation, 20, 873-922.

Ridderinkhof, K.R. (2002). Activation and suppression in conflict tasks: empirical 
clarification through distributional analyses. In W. Prinz, \& B. Hommel (Eds.), Attention and Performance, Vol. XIX, Common Mechanisms in Perception and Action (pp. 494-519). Oxford: Oxford University Press.

Ridderinkhof, K.R., Scheres, A., Oosterlan, J., \& Sergeant, J.A. (2005 ). Delta plots in the study of individual differences: new tools reveal response inhibition deficits in AD/HD that are eliminated by methylphenidate treatment. Journal of abnormal psychology, 114, 197-215.

Rubia, K., Halari, R., Smith, A.B., Mohammad, M., Scott, S., \& Brammer, M.J. (2009). Shared and disorder-specific prefrontal abnormalities in boys with pure attention deficit/hyperactivity disorder compared to boys with pure $\mathrm{CD}$ during interference inhibition and attention allocation. The Journal of Child Psychology and Psychiatry, 50, 669-678.

Rubia, K., Cubillo, A., Smith, A.B., Woolley, J., Heyman, I., \& Brammer, M.J. (2010). Disorder-specific dysfunction in right inferior prefrontal cortex during two inhibition tasks in boys with attention-deficit hyperactivity disorder compared to boys with obsessivecompulsive disorder. Human Brain Mapping, 31, 287-299.

Sánchez, C.R., Ramos, C., Díaz, F., \& Simón, M. (2010). Validación de la escala de evaluación del trastorno por déficit de atención/hiperactividad (EDAH) en población adolescente. Revista de Neurología, 50, 283-290.

Schwartz, K., \& Verhaeghen, P. (2008). ADHD and Stroop interfenrence from age 9 to 41 years: a meta-analysis of developmental effects. Psychological Medicine, 38, 1607-1616. 
Impulse capture and inhibition in ADHD

Sergeant, J. A., Geurts, H., \& Oosterlaan, J. (2002). How specific is a deficit of executive functioning for attention-deficit/hyperactivity disorder? Behavioural Brain Research, 130, 328.

Simon, J.R. (1969). Reactions toward the source of stimulation. Journal of Experimental Psychology, 81, 174-176.

Smigasiewicz, K., Ambrosi, S., Blaye, A., \& Burle, B. (2020). Inhibiting errors while they are produced: direct evidence for error monitoring and inhibitory control in children. Developmental Cognitive Neuroscience, 41, doi: 100742.

Sonuga-Barke, E.J.S., \& Castellanos, F.X. (2007). Spontaneous attentional fluctuations in impaired states and pathological conditions: A neurobiological hypothesis. Neuroscience and Biobehavioral Reviews, 31, 977-986.

Spieser, L., van den Wildenberg, W., Hasbroucq, T., Ridderinkhof, K.R., \& Burle, B. (2015). Controlling your impulses: electrical stimulation of the human supplementary motor complex prevents impulsive errors. The journal of Neuroscience, 35, 3010-3015.

Stroop, J. R. (1935). Studies of interference in serial verbal reactions. Journal of experimental psychology, 18, 643-662.

Suarez, I., Vidal, F., Burle, B., \& Casini, L. (2015). A dual-task paradigm to study the interference reduction in the Simon task. Experimental Psychology, 32, 75-88 
Tamm, L., Nakonezny, P.A., \& Hughes, C.W. (2012). An open trial of a metacognitive executive function training for young children with ADHD. Journal of Attention disorders, $18,551-559$.

Tsal, Y., Shalev, L., \& Mevorach, C. (2005). The diversity of attention deficits in ADHD: the prevalence of four cognitive factors in ADHD versus controls. Journal of learning disabilities, 38, 142-157.

Vaidya, C.J., Bunge, S.A., Dudukovic, N.M., Zalecki, C.A., Elliott, G.R., \& Gabrieli, J.D.E. (2005). Altered neural substrates of cognitive control in childhood ADHD: evidence from functional magnetic resonance imaging. American Journal of Psychiatry, 162, 1605-1613. Van den Wildenberg, W.P.M., Wylie, S.A., Forstmann, B.U., Burle, B., Hasbroucq, T., \& Ridderinkhof, K.R. (2010). To head or to heed? Beyond the surface of selective action inhibition: A review. Frontiers in Human Neuroscience, 4, 222.

Van Mourik, R. Papanikolau, A., van Gellicum-Bijlhout, J., van Oostenbruggen, J., Veugelers, D., Post-Uiterweer, A., Sergeant, J.A., \& Oosterlaan, J. (2009). Interference control in children with Attention deficit-hyperactivity disorder. Journal of abnormal child psychology, 37, 293-303.

Wechsler, D. (1991). Wechsler Intelligence Scale for Children, 3rd edn. Psychological Corporation, San Antonio, TX. 
Impulse capture and inhibition in ADHD

Weigard, A., Heathcote, A., Matzke, D., \& Huang-Pollock, C. (2019). Cognitive modeling suggests that attentional failures drive longer stop-signal reaction time estimates in attention deficit/hyperactivity disorder. Clinical Psychological Science, 7, 643-667.

Weigard A., \& Huang-Pollock, C. (2014). A diffusion modeling approach to understanding contextual cueing effects in children with ADHD. Journal of Child Psychology and Psychiatry, 55, 1336-1344.

Weller, E.B., Weller, R.A., Fristad, M.A., Rooney, M.T., \& Schecter, J. (2000). Children's interview for psychiatric syndromes (CHIPS). Journal of the American academy of Child and Adolescent Psychiatry, 39, 76-84.

White, C.N., Ratcliff, R., \& Starns, J.J. (2011). Diffusion models of the flanker task: discrete versus gradual attentional selection. Cognitive Psychology, 63(4), 210-238.

White, C.N., Servant, M., \& Logan, G.D. (2018). Testing the validity of conflict driftdiffusion models for use in estimating cognitive processes: A parameter-recovery study. Psychonomic Bulletin Review, 25, 286-301.

Winer, A.J. (1970). Statistical principles in experimental design. London: Mc Graw-Hill.

Ziegler, S., Pedersen, M.L., Movinckel, A.M., \& Biele, G. (2016 ). Modelling ADHD: a review of ADHD theories through their predictions for computational models of decisionmaking and reinforcement learning. Neuroscience and Biobehavioral Reviews, 71, 633-656. 
Impulse capture and inhibition in ADHD

\section{Table 1}

Demographic and neuropsychological variables for both groups.

\begin{tabular}{|c|c|c|c|}
\hline ADHD & non-ADHD & $t$ value & $p$ value \\
\hline Mean \pm SD & Mean \pm SD & & (Cohen's $d$ ) \\
\hline
\end{tabular}

$\begin{array}{lllll}\text { Age (years) } & 11.6 \pm 2.3 & 11.4 \pm 2.2 & 0.91 & 0.36(0.09) \\ \text { Estimated IQ } & 98.6 \pm 14.4 & 114.3 \pm 16.6 & 3.66 & <.0001(1.01) \\ \text { WMI } & 108.2 \pm 14.6 & 132.2 \pm 17.4 & 5.15 & <.0001(1.49)\end{array}$

\section{EDAH scale}

$\begin{array}{lllll}\text { Hyperactivity } & 79.8 \pm 27 & 33.7 \pm 25.3 & 5.59 & <.0001(1.76) \\ \text { Attention } & 81.3 \pm 18.5 & 30.5 \pm 16.2 & 8.84 & <.0001(2.91) \\ \text { Conduct disorder } & 76.7 \pm 30.6 & 53 \pm 24.8 & 2.9 & 0.005(0.85) \\ \text { Combined type (H+A) } & 84.7 \pm 19.6 & 27.1 \pm 19.5 & 8.96 & <.0001(2.94)\end{array}$

Note: IQ = intellectual quotient (standard scores); WMI = working memory index; EDAH scale is a behavior rating scale filled by parents (centiles are presented). 
Impulse capture and inhibition in ADHD

\section{Table 2}

Percentage of each trial type (pure correct, partial error, and error) for each group

ADHD

$65.3 \pm 13.7$

Pure correct

Partial error

Error
$9 \pm 4.18$

$5.7 \pm 3.63$
non-ADHD $\quad F$ value

$75.8 \pm 11.9$

8.1

$9.3 \pm 3.86$

.09

$3.3 \pm 1.68 \quad 7.6$ $p$ value (Cohen's $d$ )

$.006(0.82)$

$.77(0.08)$

$.008(0.87)$ 


\section{Table 3}

Correlation analyses.

$$
\text { Incorrect activation rate Correction rate }
$$

ADHD group

IQ

WMI

Non-ADHD group

IQ

$0.22 ; p=.30$

$0.32 ; \mathrm{p}=.13$

WMI

$0.24 ; p=.30$

$0.27 ; p=.24$
$0.22 ; p=.34$

$0.06 ; p=.77$

$0.15 ; p=.48$

$0.28 ; \mathrm{p}=.18$

Note: IQ = intellectual quotient; WMI = working memory index. 
Figure 1. Example of a partial error and of chronometric indices

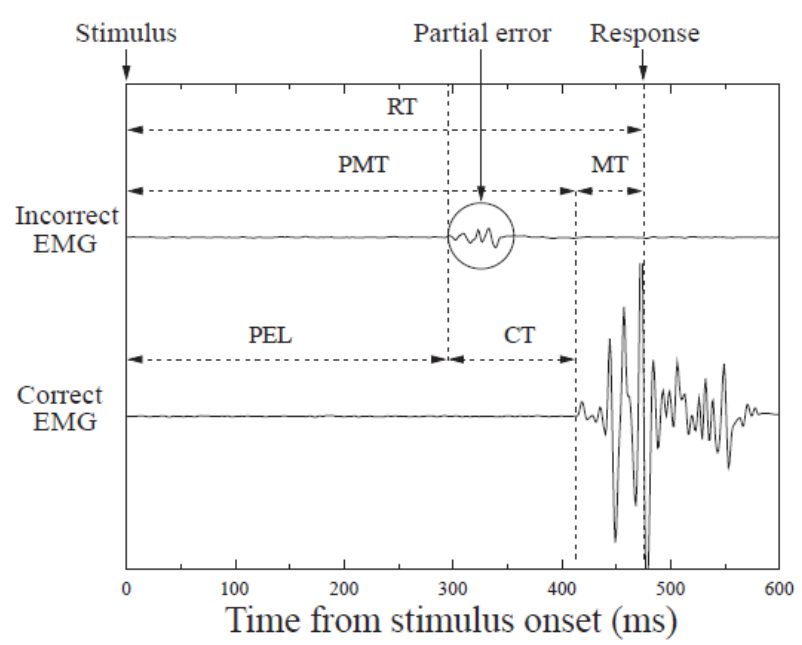

Note: Electromyographic (EMG) activity from muscles involved in the incorrect (upper trace) and the correct (lower trace) responses. The vertical continuous line indicates the onset of the stimulus and the vertical dashed line indicates the mechanical button-press response. The correct response was preceded by a small EMG activity (partial error) recorded in the muscle involved in the incorrect response. This small activity was too weak to trigger a real error. Chronometric indices are illustrated on the EMG activity from muscles involved in the incorrect and the correct responses. Abbreviations: RT: Reaction time (from the stimulus onset to the response button press); PMT: Premotor time (from the stimulus onset to the correct EMG onset); MT: Motor time (from the correct EMG onset to the button press); PEL: Partial error latency (from the onset stimulus to the EMG onset of the incorrect response); CT: Correction time (from the incorrect EMG onset to the correct one). 
Impulse capture and inhibition in ADHD

Figure 2. Overall Simon task performance.
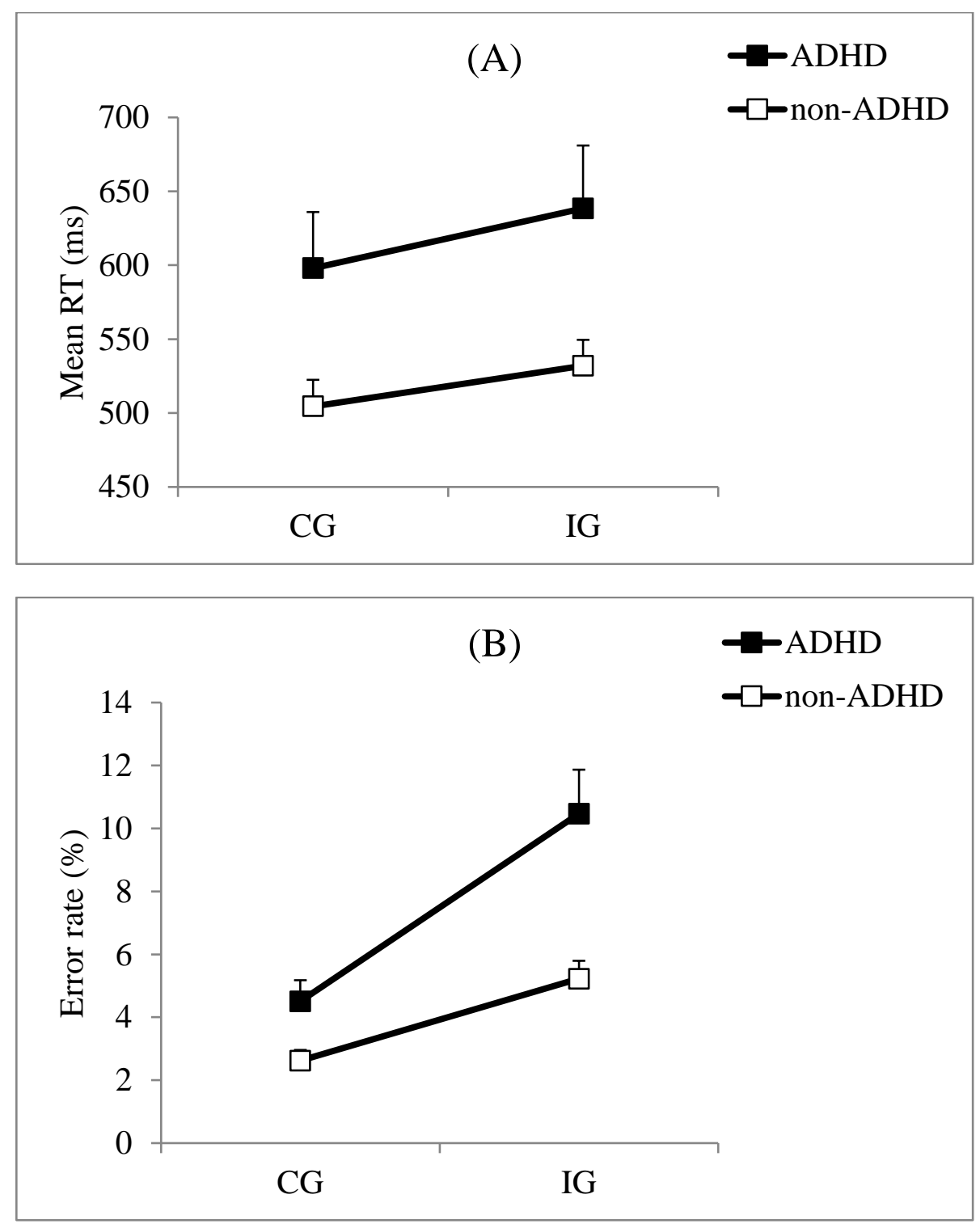

Note: Mean reaction times (A) and error rates (B) for congruent (CG) and incongruent (IG) trials in non-ADHD children and children with ADHD. Error bars are mean standard errors. 
Impulse capture and inhibition in ADHD

Figure 3. Incorrect activation rate and correction rate.
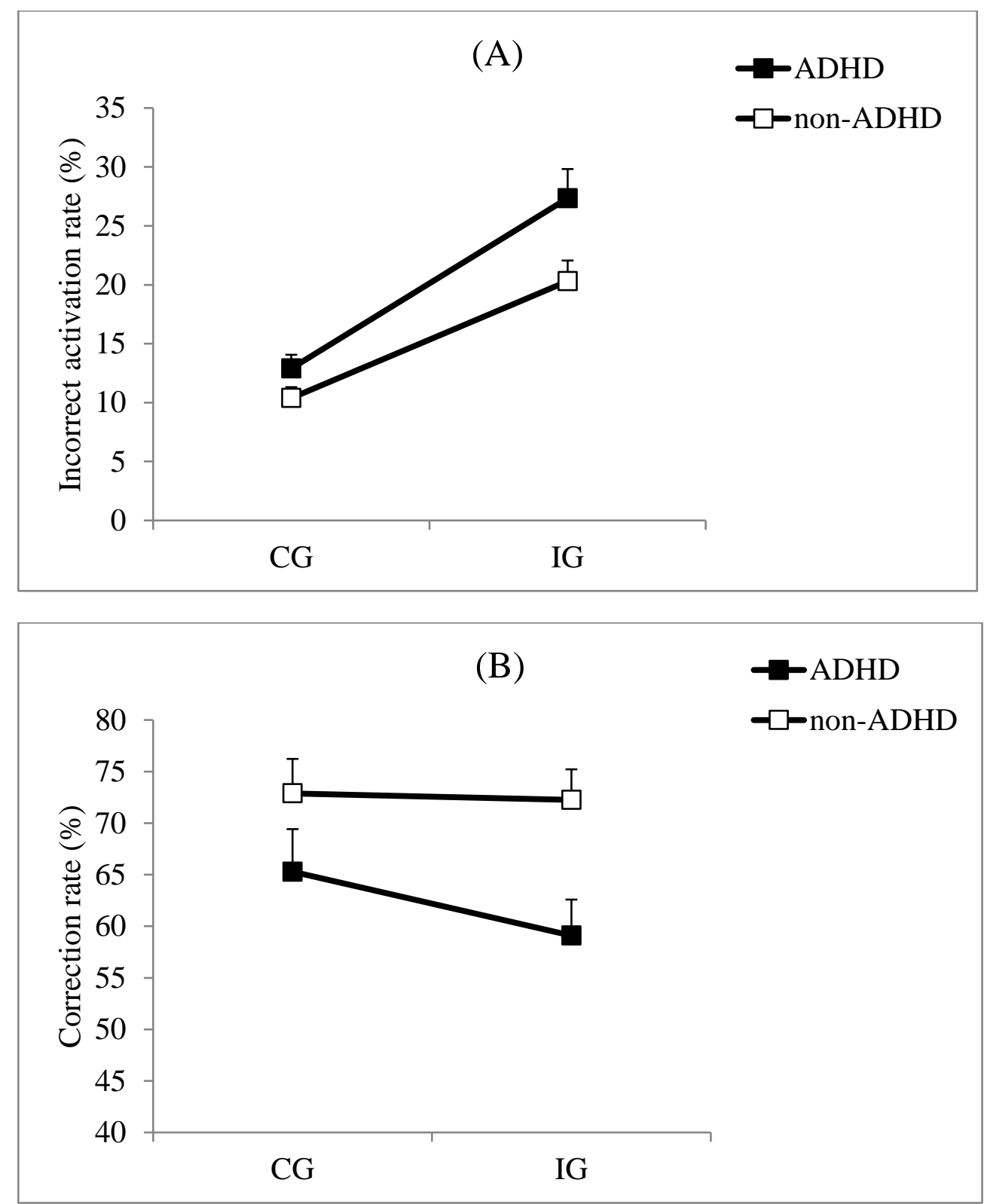

Note: (A) Incorrect activation rate corresponding to the sum of both partial errors and real errors, and (B) correction rate corresponding to the ratio between the number of partial errors and the number of incorrect activations in congruent (CG) and incongruent (IG) trials in nonADHD children and children with ADHD. Error bars are mean standard errors. 
Figure 4. Chronometric indices for pure correct trials.

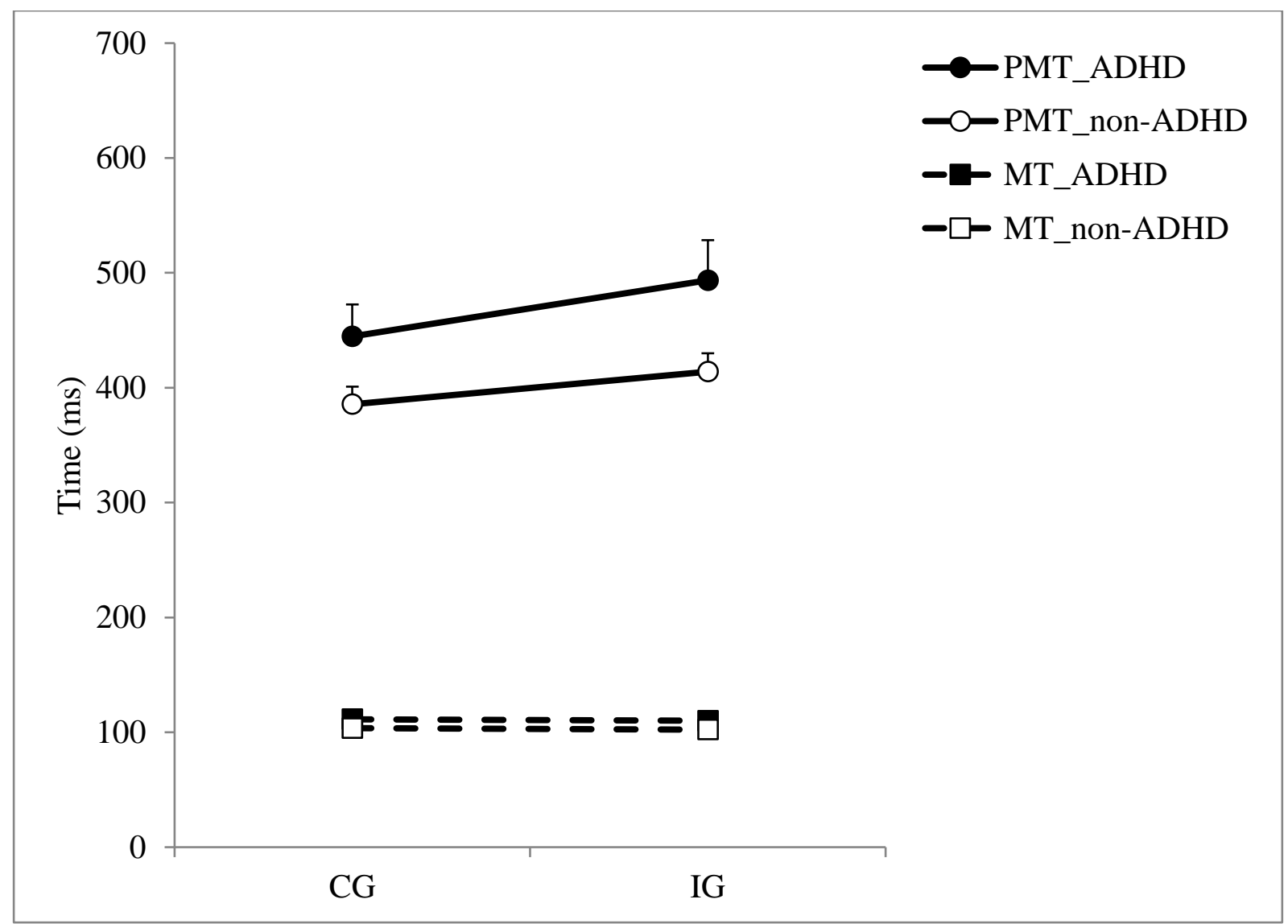

Note: Mean premotor time (PMT) (latency between the stimulus onset and the EMG onset) and mean motor time (MT) (latency between the EMG onset and the button press) in congruent (CG) and incongruent (IG) trials, in non-ADHD children and children with ADHD. Error bars are mean standard errors. 
Figure 5. Chronometric indices for partial error trials.
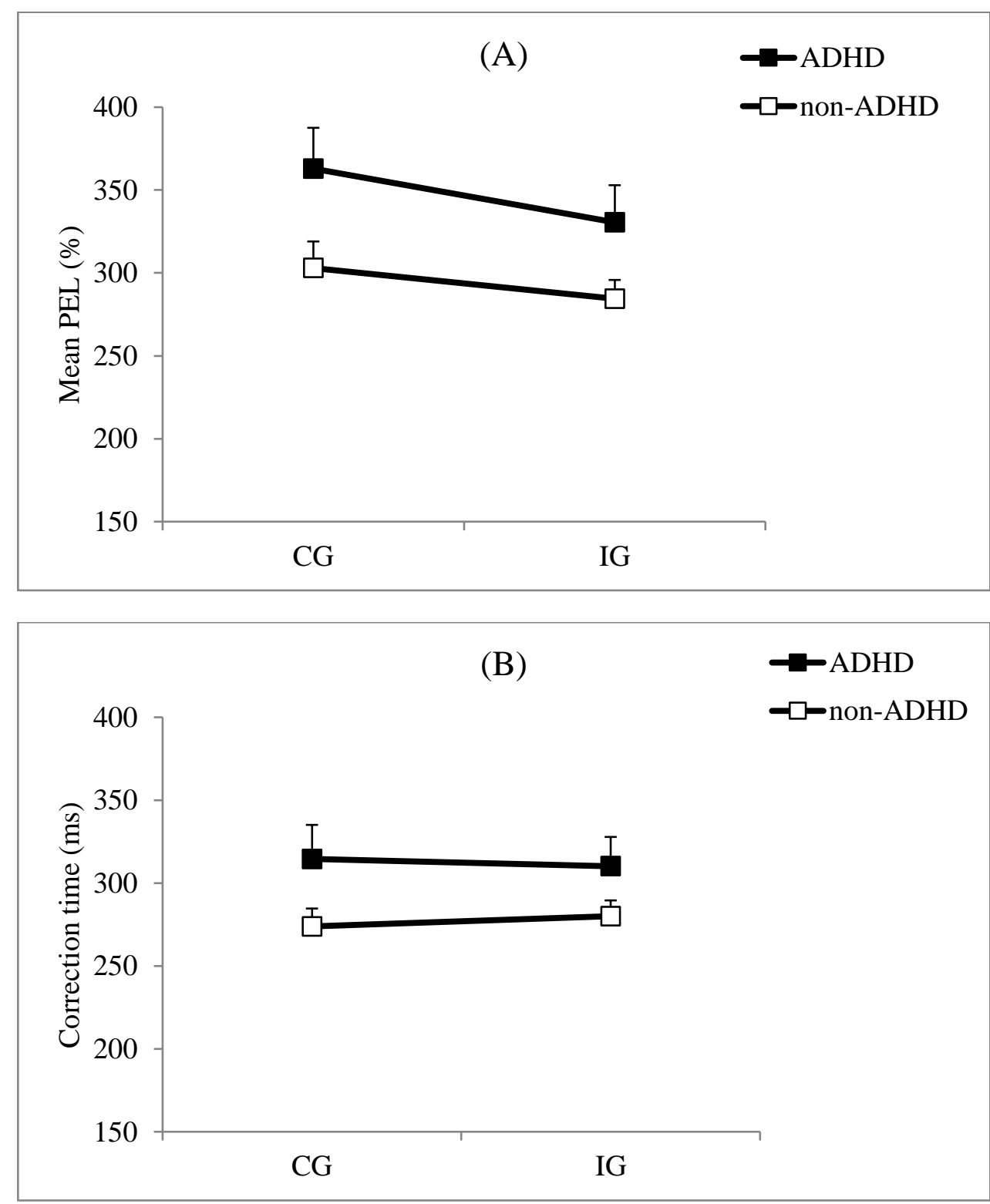

Note: Mean partial error latency (A) corresponding to the interval between the stimulus onset and the EMG onset of the incorrect response, and mean correction time (B) corresponding to the latency between the incorrect EMG onset and the correct EMG onset, in congruent (CG) and incongruent (IG) trials, in non-ADHD children and children with ADHD. Error bars are mean standard errors. 


\section{Legends of figures}

Figure 1. Example of a partial error and of chronometric indices. Electromyographic (EMG) activity from muscles involved in the incorrect (upper trace) and the correct (lower trace) responses. The vertical continuous line indicates the onset of the stimulus and the vertical dashed line indicates the mechanical button-press response. The correct response was preceded by a small EMG activity (partial error) recorded in the muscle involved in the incorrect response. This small activity was too weak to trigger a real error.

Chronometric indices are illustrated on the EMG activity from muscles involved in the incorrect and the correct responses. Abbreviations: RT: Reaction time (from the stimulus onset to the response button press); PMT: Premotor time (from the stimulus onset to the correct EMG onset); MT: Motor time (from the correct EMG onset to the button press); PEL: Partial error latency (from the onset stimulus to the EMG onset of the incorrect response); CT: Correction time (from the incorrect EMG onset to the correct one).

Figure 2. Overall Simon task performance. Mean reaction times (A) and error rates (B) for congruent (CG) and incongruent (IG) trials in non-ADHD children and children with ADHD. Error bars are mean standard errors.

Figure 3. Incorrect activation rate and correction rate. (A) Incorrect activation rate corresponding to the sum of both partial errors and real errors, and (B) correction rate corresponding to the ratio between the number of partial errors and the number of incorrect activations in congruent (CG) and incongruent (IG) trials in non-ADHD children and children with ADHD. Error bars are mean standard errors. 
Figure 4. Chronometric indices for pure correct trials. Mean premotor time (PMT) (latency between the stimulus onset and the EMG onset) and mean motor time (MT) (latency between the EMG onset and the button press) in congruent (CG) and incongruent (IG) trials, in nonADHD children and children with ADHD. Error bars are mean standard errors.

Figure 5. Chronometric indices for partial errors trials. Mean Partial error latency (A) corresponding to the interval between the stimulus onset and the EMG onset of the incorrect response, and mean correction time (B) corresponding to the latency between the incorrect EMG onset and the correct EMG onset, in congruent (CG) and incongruent (IG) trials, in nonADHD children and children with ADHD. Error bars are mean standard errors. 